\title{
EDUCAÇÃO NÃO-FORMAL E COMUNIDADE TERAPÊUTICA PARA DEPENDENTES QUÍMICOS: ARTICULAÇÃO DE PROCESSOS EDUCATIVOS EM PRÁTICAS SOCIAIS
}

\author{
M. C. LUIZ* e R. M. GOMES \\ Universidade Federal de São Carlos - UFSCar \\ cecilialuiz@ufscar.br*
}

Artigo submetido em setembro/2013 e aceito em julho/2015

DOI: 10.15628/holos.2015.1645

\begin{abstract}
RESUMO
Este artigo tem como intenção refletir sobre processos socioeducativos em ambientes denominados comunidades terapêuticas que ajudam na recuperação de adolescentes e jovens dependentes químicos, no período (mínimo) de seis meses a um ano, com liberdade restringida. Trata da questão do aumento de número de dependentes químicos no Brasil, e também de educadores (monitores) que atuam nestas comunidades, com vistas à educação não-formal. Tevese como metodologia, uma pesquisa intervenção por meio do programa de tratamento, que objetiva possibilitar que os dependentes químicos revejam suas ações segundo parâmetros diferentes dos que os conduziam antes da internação. O tratamento segue alguns pressupostos básicos, com vistas a originar
\end{abstract}

reflexão sobre a capacidade de entender, querer e superar o uso das substâncias psicoativas, isto é, tomar decisões e desenvolver seu projeto de vida. A ideia é que na Comunidade Terapêutica deve-se refletir constantemente sobre questões a serem evitadas, como: falta de formação continuada para os educadores (monitores); desrespeito à legislação trabalhista; uso criminoso de medicações controladas, e quadros de práticas de violências (simbólicas e/ou de fato), pois ela surgiu como alternativa às rígidas estruturas do sistema psiquiátrico. Concluiu-se que se a comunidade terapêutica não tiver essa preocupação em repensar-se, a partir de suas práticas, dificilmente, poderá ser uma alternativa útil à sociedade.

PALAVRAS-CHAVE: educação não-formal; comunidade terapêutica; processos educativos.

\section{NON-FORMAL EDUCATION AND THERAPEUTIC COMMUNITY FOR DRUG ADDICTS: ARTICULATION OF EDUCATIONAL PROCESSES IN SOCIAL PRACTICES}

\begin{abstract}
This article is intended to reflect upon those processes in environments referred to as therapeutic communities that help in the recovery of adolescents and young drug addicts, in the (minimum) period of six months to a year, with restricted freedom. Deals with the question of the increase of the number of drug addicts in Brazil, and also of educators (monitors) that operate in these communities, with a view to non-formal education. Had itself as methodology, an intervention research through the treatment program, which aims to enable the chemical dependents to review their actions according to different parameters of the led before the hospitalization. The treatment follows some basic
\end{abstract}

assumptions, in order to lead to reflection on the ability to understand and overcome the use of psychoactive substances, i.e., make decisions and develop their life project. The idea is that in Therapeutic Community must constantly reflect on issues to be avoided, such as: lack of continuing education for educators (monitors); outraging labor legislation; criminal use of controlled medications, and violence practices frames (symbolic and/or in fact) because it arose as an alternative to the rigid structures of the psychiatric system. It was concluded that if the therapeutic community does not have this concern to rethink themselves, from their practices, hardly, may be a useful alternative to society.

KEYWORDS: non-formal education; therapeutic community; educational processes. 


\section{INTRODUÇÃO}

O abuso de drogas verificado nos últimos anos e suas consequências na vida dos indivíduos e da sociedade tem sido considerado um problema de saúde pública. A situação vem se tornando cada vez mais alarmante e com grande impacto social. Segundo Bucher (1992),

(...) o problema espalha-se nas sociedades industrializadas para atingir dimensões epidêmicas, transformando-se num sintoma inquietante de um novo e profundo mal-estar na civilização. (BUCHER, 1992, p. 35).

Este artigo tem como objetivo refletir sobre a articulação de processos sócio educativos em práticas sociais, com foco na perspectiva da educação não-formal (GOHN, 2006) em ambientes como Comunidades Terapêuticas para dependentes químicos. Uma Comunidade Terapêutica lida com a problemática de educar seus internos de forma involuntária, e trabalha na recuperação de adolescentes e jovens dependentes químicos, no período (mínimo) de seis meses a um ano, com liberdade restringida. Esse estudo se justifica, na medida em que, hoje, apesar dos malefícios das drogas serem mais divulgado, existe um aumento de adolescentes e jovens com dependência química, que infelizmente, deveriam/poderiam estar cursando a Educação Básica; e de educadores sem maiores conhecimento sobre possibilidades de enfrentamento do problema do uso/abuso de substâncias psicoativas. Além disso, há certa ignorância a respeito do que esses adolescentes e jovens aprendem ou vivenciam nestes locais de tratamento. O problema do uso/abuso de substâncias que alteram o estado mental não é uma característica apenas do mundo moderno. $\mathrm{O}$ uso de substâncias psicoativas faz parte da realidade dos seres humanos desde tempos remotos. Destaca-se que, em sociedades de menor grau de complexidade, pertencentes ao período pré-capitalista, o uso de substâncias (alteradoras de percepção) tinha a finalidade de estabelecer contatos com eventuais entidades/divindades. $O$ uso dos psicoativos envolvia formas de religiosidade, por exemplo, o uso do peyote (Lopophora Williansi) entre indígenas mexicanos. Atualmente, o uso de Ayahuasca (Santo Daime), considerado por alguns psiquiatras como alucinógeno, no Brasil é utilizado como exercício de religiosidade, muito embora esse culto tenha surgido no início do século XX na Amazônia, também se assemelha ao tipo de uso das sociedades pré-modernas. Assim, o uso é uma característica das sociedades humanas. Países industrializados como EUA e Europa Ocidental, já na década de 1950, encontravam intensa crítica por parte de setores de sua sociedade e isso propiciou o surgimento de movimentos como os beatniks dos anos 50 e os hippies dos anos 60 e 70 . Esses grupos assumiram posturas radicalizantes diante do modelo moral de sua sociedade e aderiram ao experimentalismo estético nas artes e na música em geral; um romântico apelo à liberdade e à contestação política.

Ressalta-se que, hoje, nas Comunidades Terapêuticas encontram-se adolescentes e jovens que possuíam noções precisas dos problemas causados pelo uso/abuso dos psicoativos, mas, mesmo assim, não deixaram de experimentá-los. Mais grave ainda é viver numa sociedade em que o crack é considerado uma epidemia, no qual o narcotráfico se constitui como economia paralela que movimenta somas maiores que o PIB (Produto Interno Bruto) de muitos países. É, também, uma das principais fontes de violência e instabilidade social, a ponto de ter-se que repensar o universo jurídico de tratamentos para esses problemas. No contexto epidêmico do 
crack, criou-se a necessidade de atendimento para essa crescente demanda à Saúde Pública que são os tratamentos para os usuários. Estes envolvem alternativas, como: voluntário, involuntário e coercitivo, nos termos da Lei 10.216/2001 que, segundo algumas tendências mais liberais, foi superada pela Lei $11.343 / 2006$. Esta última, não prevê diretamente a possibilidade de uma internação involuntária, que é causadora de grande controvérsia. É importante esclarecer que uma internação voluntária é feita com a concordância do usuário de substâncias psicoativas; a internação involuntária é feita sem a concordância do dependente químico e, geralmente, começa com um "resgate" (a expressão correta é "sequestro") feito pelas equipes das Comunidades Terapêuticas; e a internação coercitiva, que é uma determinação judicial aplicada como sentença alternativa pelo julgador, em casos em que, pelo problema da dependência, o indivíduo pratica crimes de menor potencial lesivo contra a sociedade. Na primeira e na terceira opção de tratamento (voluntário e coercitivo) não há muito que discutir, exceto sobre necessidade de qualidade nos tratamentos e o respeito aos direitos humanos. $O$ que causa grande comoção é a internação involuntária, seja essa por determinação familiar ou por determinação do Poder Executivo, como aconteceu durante esse ano de 2012, em cidades como São Paulo e Rio de Janeiro.

Em linhas gerais, o que está em jogo é saber se uma internação pode ser determinada involuntariamente, por familiares ou pelo Poder Público a revelia da vontade do usuário de substâncias psicoativas. Trata-se de compreender se essa medida fere ou não os preceitos e garantias constitucionais relacionados à cidadania no Brasil, em especial, o direito de ir e vir e o direito de ninguém ser privado de sua liberdade, exceto por condenação após o trânsito em julgado de sentença judicial, depois do exercício do contraditório e da ampla defesa. Estes três princípios constitucionais afrontam a internação involuntária, mas, esclarece-se que essa é uma questão a ser aprofundada em pesquisas na área jurídica, não sendo o objetivo deste texto. Apenas sinalizou-se esta discussão, devido à outra problemática que é a recuperação desses adolescentes e jovens durante o período de internação (muitas vezes, involuntária), com vistas a reintegrá-lo na sociedade.

\section{COMO SE CONSTITUÍRAM AS COMUNIDADES TERAPÊUTICAS?}

O tratamento em Comunidades Terapêuticas se caracterizou, no século XX, como possibilidade de atenção/atendimento menos invasiva (FRACASSO, 2002; DE LEON, 2003) em relação às internações psiquiátricas. Inicialmente fundamentava-se na convivência entre iguais em um ambiente protegido da presença de substâncias psicoativas, e que fornecia uma estrutura com menos grau de hierarquização tendente a composições mais democráticas de pacificação das demandas surgidas na convivência entre residentes e terapeutas, e principalmente entre residentes e residentes. O aumento do número de internações desde a década de 1960 cresceu de forma exponencial, em função do papel exercido pelas substâncias psicoativas em especial no mundo ocidental, e isso acabou por tornar as Comunidades Terapêuticas um negócio altamente lucrativo, sem que isso se refletisse necessariamente em qualidade de tratamento. Esse acrescente propiciou uma perspectiva de "negócio isento de taxação", na medida em que essas instituições, majoritariamente, se enquadram como instituições filantrópicas. As taxas estabelecidas para institucionalizar uma Comunidade Terapêutica no Brasil são consideradas baixas, o que acaba por incentivar a criação de inúmeras instituições que o Estado não consegue acompanhar. Sem fiscalização devida, estes locais de atendimento aos usuários de drogas 
funcionam com sérios prejuízos para a sociedade, além de utilizarem, muitas vezes, pessoas despreparadas para o trato com os residentes. Em alguns casos, chega-se a situações críticas como denúncias por maus-tratos e formas diversificadas de violência, atestando com isso falta de preparo e habilidade para lidar com esse tipo de situação.

No Brasil, segundo Fracasso (2002), as Comunidades Terapêuticas surgem por volta da década de 1960, vinculadas normalmente as instituições de orientação religiosa católica ou protestante. Essas comunidades estavam ligadas à assistência social e eventualmente à saúde pública nos municípios. Nesta época, havia falta de lei específica que disciplinasse o funcionamento dessas instituições, situação esta que se modificou com promulgação de legislação própria, com vistas a indicar as condições mínimas e necessárias de funcionamento para as Comunidades Terapêuticas. A partir de 2001, as Comunidades Terapêuticas foram disciplinadas por legislação específica, a RDC 101/2001 ANVISA. Esse dispositivo legal foi um avanço no sentido de estabelecer as condições físicas minimamente exigidas para que recebessem indivíduos para tratamento. Além disso, criou-se categorias que determinavam os casos de internação, que poderiam ou não ser aceitos pelas Comunidades Terapêuticas. Essa medida refletiu uma política mais humanizada e preocupada com os residentes. Contudo, a RDC 101/01 foi substituída por um dispositivo bem mais "brando", a RDC 29/2011, com o qual discorda terminantemente a Associação Brasileira de Psiquiatria (ABP), conforme matéria registrada no seu site. A ABP considera muito preocupante essa mudança na política utilizada pela Agência Nacional de Vigilância Sanitária (ANVISA), já que a simplificação das regras de funcionamento tende a colocar em risco os indivíduos em tratamento. Com a nova legislação (RDC 29/2011), entre outros problemas detectados pela ABP, as comunidades necessitam apenas de um técnico com nível superior nos seus quadros de prestadores de serviços, sem exigência de formação em medicina, portanto, sem necessidade de responder ao Conselho Federal de Medicina (CFM). A ABP entende que não é adequado que usuários de substâncias lícitas e/ou ilícitas sejam "tratados" sem as orientações de um médico psiquiatra (especialista em doenças mentais). Essa nova legislação, a RDC 29/2011 contraria a Lei 10.216/2001 que orienta sobre a proteção de direitos das pessoas com necessidades especiais com transtorno mentais (segundo a Organização Mundial da Saúde este tipo de transtorno é reversível), como é o caso de uso das substâncias psicoativas. Além disso, a RDC 29/2011 também possibilita que as Comunidades Terapêuticas não tenham obrigação de contratar médicos plantonistas para os eventuais problemas devido ao quadro de abstinência que aconteçam no local de tratamento. Com essa nova legislação, os indivíduos internados passam a ser vistos como "acolhidos", o que significa simplesmente a troca de expressões, uma vez que a submissão ao tratamento e às regras internas é a mesma. Segundo a agência de notícias virtual Isaúde.net:

(...) A ABP é favorável que clínicas especializadas e hospitais psiquiátricos, sejam os locais adequados a este e outros tipos de doenças mentais e que deveriam ser elaborados tratamentos específicos para todas as necessidades de internação, com programas para cada uma delas, inclusive o grave problema da dependência química. Por estes motivos, a ABP enviou ofício à Anvisa pedindo a imediata revogação da Resolução RDC 29, e se prontifica a participar de uma discussão séria e responsável para a formulação de uma política pública de atendimento aos doentes mentais e dependentes químicos, inclusive contribuindo para a qualificação e fiscalização das Comunidades Terapêuticas, sempre dentro do rigor das melhores práticas médicas (ISAÚDE.NET, 2015). 
Desta forma há uma polêmica legítima em torno das internações, seja na modalidade voluntária ou involuntária em Comunidades Terapêuticas, uma vez que, pela nova legislação (RDC 29/2011), tais comunidades não estão obrigadas a oferecer as condições mínimas necessárias de segurança ao público com dependência química, conforme a ABP. Mas, afinal, o define uma Comunidade Terapêutica? Segundo De Leon (2003),

(...) a expressão "comunidade terapêutica" conota uma comunidade capaz de remediar, restaurar ou curar. Mas a distinção profunda entre a CT e outros tratamentos reside no uso da comunidade como método para mudar a pessoa inteira (DE LEON, 2003, p. 100).

Uma Comunidade Terapêutica deve ter um ambiente de atendimento a dependentes químicos, cujo principal método ou instrumento de tratamento é a convivência temporária entre grupos de indivíduos que partilham certos objetivos comuns, como por exemplo, alcançar a abstinência total ou parcial de substância(s) de uso/abuso. É considerada, também, uma das modalidades de tratamento oferecida a usuários de substâncias psicoativas lícitas e/ou ilícitas no Brasil, basicamente, funciona como uma micro sociedade em que os residentes se submetem a um programa de tratamento. No convívio entre iguais, busca-se refletir sobre as decisões relativas a usar ou não substâncias psicoativas, e, também, a formar um novo repertório de arranjos e rearranjos na vida coletiva. A perspectiva é que o residente ao sair do programa de tratamento tenha condições de reorientar sua vida em parâmetros diferentes dos que o conduzia antes da internação.

\section{COMUNIDADE TERAPÊUTICA E O TRATAMENTO}

O tratamento em Comunidade Terapêutica segue alguns pressupostos básicos, com vistas a originar reflexão nas pessoas sobre suas capacidades de entender, querer, decidir e superar o uso das substâncias psicoativas. Precisam fazer escolhas, tomar decisões e desenvolver, com auxílio da equipe, seu próprio projeto de vida. O que mantém a coesão de propósitos nesse tipo de convivência (FRACASSO, 2002) são princípios, como: compartilhamento entre os pares das experiências e esperanças; honestidade; não verticalização das relações (como acontecia, geralmente, nas internações psiquiátricas tradicionais); e espiritualidade, no sentido de reconhecimento de um ser superior, como possibilidade de obter outra referência para as relações e compromissos morais no estabelecimento das relações sociais. Esses princípios não devem estar explicitados de qualquer forma na Comunidade Terapêutica, mas organizados naquilo que se denomina: "Programa de Tratamento". Esse programa especifica as atividades diárias, tanto físicas quanto as que envolvem estudos mais intelectuais, como discussões em grupos de assuntos gerais (inclusive as de ordem religiosa e/ou teológica das Comunidades Terapêuticas). Com essa organização em Programa de Tratamento articula-se a Comunidade Terapêutica na perspectiva da educação não-formal. Ao explicitar de forma coerente e interativa os objetivos do programa, e como estão organizadas as atividades e as relações no ambiente de convívio, a Comunidade Terapêutica informa aos eventuais residentes sobre começo, meio e fim do tratamento. Nesta perspectiva, por este programa ter características de educação não-formal os familiares percebem a importância deste processo educativo nas vidas destes adolescentes e jovens, e a possibilidade de inseri-los, novamente, no convívio social de forma mais reflexiva. 
A ideia de "comunidade", a princípio torna-se cativante, mas as regras devem ser claras, com vistas a possibilitar o que está se chamando de tratamento, para que, não se confunda o seu significado:

\begin{abstract}
Ela sugere uma coisa boa: o que quer que "comunidade" signifique, é bom "ter uma comunidade," "estar numa comunidade". Se alguém se afasta do caminho certo, frequentemente explicamos sua conduta reprovável dizendo que "anda em má companhia". Se alguém se sente miserável, sofre muito e se vê persistentemente privado de uma vida digna, logo acusamos a sociedade - 0 modo como está organizada e como funciona. As companhias ou a sociedade podem ser más; mas não a comunidade. Comunidade, sentimos, é sempre uma coisa boa. Os significados e sensações que as palavras carregam não são, é claro, independentes. "Comunidade" produz uma sensação boa por causa dos significados que a palavra "comunidade" carrega - todos eles prometendo prazeres (BAUMAN, 2003, p. 7).
\end{abstract}

Assim, a convivência na Comunidade Terapêutica, tendo por conteúdo os princípios elencados para fundamentar o Programa de Tratamento, pode se constituir em um ambiente propício para que os usuários de substâncias psicoativas lícitas e/ou ilícitas repensem decisões sobre suas vidas e, a partir daí, trabalhem na construção de uma perspectiva que permita a superação ou equilíbrio desta situação de dependência química. Esse aspecto de construção e projeção do individuo é muito importante na medida em que envolve práticas que são "condicionadas", como acontece com o uso de drogas. A perspectiva de um recomeçar pode esbarrar em questões relativas ao ambiente onde se dá o processo. É por isso que os Programas de Tratamento devem ser apresentados de forma esclarecedora para os residentes e seus familiares. Sem uma decisão consciente, as chances de resultados positivos podem ficar comprometidas. O que é mais interessante, é que tanto no ambiente escolar como na Comunidade Terapêutica, o principal tratamento é despertar o interesse do indivíduo pelas aprendizagens e mudanças. Pensar projeto de vida, para pessoas que vivem em Comunidades Terapêuticas significa fazer parte de um Programa de Tratamento; e, é nesse sentido, que a educação não-formal pode ser um aliado eficaz.

\title{
4 COMUNIDADE TERAPÊUTICA E A EDUCAÇÃO NÃO-FORMAL
}

Ao estabelecer um vínculo entre a internação para tratamento de dependentes químicos e a educação, compreende-se que os processos educativos podem e devem estar presentes em um ambiente que se caracterize por ser terapêutico. Sabe-se que o comportamento individual e a formação da consciência moral e dos ideais são moldados por meio de valores transmitidos, principalmente, na família e na escola. Infelizmente, a dimensão que atinge hoje o fenômeno do consumo de drogas nos grandes centros urbanos brasileiros traz um sentimento de medo, insegurança e sensação de impotência para os familiares de adolescentes e jovens, com grande preocupação dos seus parentes vivenciarem tal situação. Lembrando que o primeiro contato com as drogas, muitas vezes, ocorre na adolescência; e que é nessa fase, que o indivíduo passa por bruscas mudanças biológicas e psíquicas, sendo a etapa mais vulnerável de todo o desenvolvimento humano. Conflitos de naturezas diversas afloram num momento de labilidade emocional e extrema sensibilidade. $\mathrm{O}$ ambiente da Comunidade Terapêutica deve ser favorável a apreensão de saberes e práticas que auxiliem estes dependentes químicos por meio de um 
programa de tratamento, e se reposicionem em relação à sua existência. Para tanto, uma comunidade deve também ser apta a auto avaliar-se, com uma perspectiva de não apenas "ensinar" o diálogo, mas de praticá-lo.

Segundo Gohn (2006), a educação não-formal e suas contribuições para o pleno desenvolvimento de pessoas (assim como para o desenvolvimento de mecanismos que permitem a inclusão social), vai além de uma simples integração do indivíduo na sociedade. Desta forma, a educação não-formal tem caráter de intencionalidade, que permite às pessoas a troca de aprendizagens a fim de que todos possam adquirir ferramentas necessárias à prática da cidadania.

Para a autora (ibidem, 2006), a educação formal é aquela que é ministrada pelo professor em ambientes normatizados, como a escola, seguindo um currículo. Dentre os objetivos propostos, este tipo de educação busca a aprendizagem dos alunos de conteúdos historicamente construídos, oferecendo a eles certificação ao final de cada etapa, o que permite a essas pessoas seguir para graus mais elevados de ensino. A educação informal é aquela que está relacionada à aprendizagem com o "outro" de valores, culturas, atitudes, comportamentos, adquiridas no processo de socialização, seja na família, bairro, amigos, entre outros. Aqui o ambiente em que se dá aprendizagem é espontâneo, isto é, a aprendizagem ocorre onde se desenvolvem as relações sociais, sem sistematização, e os resultados acontecem a partir do senso comum. Como já foi dito, a educação não-formal tem uma intencionalidade em si, e acontece a partir de processos de compartilhamento de experiências, sendo que os locais em que acontecem a aprendizagem são aqueles em que há processos interativos intencionais. Sua finalidade é a formação de sujeitos, com vistas a se tornarem cidadãos do mundo. Os objetivos dessa aprendizagem são construídos em conjunto, proporcionando aos indivíduos "se tornarem cidadãos do mundo, no mundo" (GOHN 2006, p.29). A organização da aprendizagem está pautada sobre os aspectos subjetivos do grupo, tendo a intencionalidade política como cerne da aprendizagem. As pessoas podem ou não participar, segundo Gohn (2006, p.29), (...) "há na educação não-formal uma intencionalidade na ação, no ato de participar, de aprender e de transmitir ou trocar saberes". Ao articular-se educação formal e não-formal (ressalta-se que uma não substitui a outra), propicia-se o desenvolvimento de mecanismos para o aprendizado da cidadania. Com isso, adquirem-se conhecimentos normativos e valores que orientam as práticas sociais, com respeito à diversidade. Assim, a educação não-formal é mais do que uma forma de aprendizado, torna-se uma proposta sociopolítica. Ao refletir-se sobre essas questões, questionase: Qual seria a ligação da educação não-formal nas Comunidades Terapêuticas?

A educação não-formal oferece, aos residentes, atividades que proporcionam não só a aprendizagem de conteúdos formais, mas também leva a transformação pessoal no coletivo. Ao promover um espaço mais democrático e com maior participação na comunidade, propiciam-se mudanças de hábitos nos adolescentes e jovens, ajudando-os na prática a ouvir mais uns aos outros. Pode-se pensar que é no respeito às diferenças, que se resolvem problemas relacionados à violência e indisciplina dentro e fora da sociedade. Qualquer instituição (sendo Comunidade Terapêutica ou escola) só promoverá efetiva transformação dos seus agentes quando a educação formal e/ou não-formal, de maneira geral, proporcione uma cultura organizacional mais democrática (com a contribuição de todos, por meio do diálogo), e com eficaz qualidade de ensino. Um bom exemplo disso é a leitura de literaturas clássicas, ou não, escolhidas pelo grupo (residentes e profissionais), de forma dialogada. Durante essa leitura, cria-se um espaço de 
diálogo, em que as pessoas, independente de sua idade, sexo, nacionalidade, nível escolar, participem socializando suas experiências, com vistas a aprender com a vivência do outro. Sendo assim, é mais que uma leitura ou interpretação de texto, é uma transformação coletiva.

\section{ALGUMAS CONSIDERAÇÕES}

Um processo educativo, na perspectiva da educação não-formal (GOHN, 2006) em Comunidades Terapêuticas para dependentes químicos deve inserir o indivíduo na sociedade com alterações de seus valores interiores (crenças, objetivos etc.), e exteriores (grupos de convívio, ações no coletivo etc.). Ao se propor uma reflexão sobre o tema, buscou-se trazer questões que estão sendo vivenciadas, mas que ainda, necessitam de estudos mais aprofundados. Nesta consideração final são abordadas apenas três inquietações, que se julgou ser importante:

A primeira, diz respeito a uma tendência humana de evocar fatos de forma positiva na memória. Neste sentido, os residentes tendem a minimizar os problemas que têm ou tiveram com as drogas, recordam-se somente de aspectos que lhes são favoráveis. Tal uso da memória, ainda que involuntariamente, é um problema para a mudança de hábitos. Mesmo que sejam pequenas distorções da realidade cotidiana, se constituem em uma forma de autoengano inconsciente, o que acaba por comprometer negativamente a revisão que o residente deve fazer de suas próprias escolhas e decisões. Assim, o residente traz o passado como "realizações pessoais" incompreendidas pelo todo social, e não rompe com os hábitos anteriores, apenas protela novas incursões de uso/abuso. Em contrapartida, se este perceber os atos passados como passíveis de necessárias mudanças, há uma chance maior de se obter sucesso no processo de tratamento. Essa questão é bem mais importante do que possa parecer em uma primeira consideração. $O$ indivíduo tende a manter na memória as situações boas e esquecer as traumáticas, até mesmo como defesa existencial, sobre esse aspecto, diz MORRISH (1975) que:

Os eus que nós somos são, em grande parte, o produto dos nossos contatos sociais; é da sociedade que obtemos o instrumento indispensável da linguagem, os nossos interesses e os nossos padrões morais básicos; os eus mudam com as transformações da sociedade. Em educação, estamos ajudando os indivíduos a se prepararem para essas transformações sociais e se adaptarem a elas (MORRISH, 1975, p. 221).

Morrish (1975) continua a discussão a partir do pensamento de Mead, e salienta a grande e justa importância que esse autor creditava ao ato educativo/construtivo do sujeito:

A consciência de identidade não surge da ação da pessoa individualmente, mas da interação, depois de uma pessoa ter percebido outras pessoas e estabelecido algum sentido de relação com elas, e de ter formado alguma idéia do modo como as ações ou comportamentos são provocados. Somente quando esse sentido de iniciar está presente é que podemos dizer que existe os primórdios da personalidade (MORRISH, 1975, p. 220).

Quando a convivência na Comunidade Terapêutica, por meio da linguagem, altera os valores dos residentes, auxilia efetivamente a formação de condições favoráveis ao desenvolvimento de um quadro de abstinência consciente. 
A segunda inquietação que se vislumbra nas Comunidades Terapêuticas, refere-se à dificuldade de desenvolver um trabalho sócio educativo de qualidade na falta de formação continuada de educadores (monitores). Estes profissionais necessitam de uma melhor definição das suas funções, e principalmente, de conhecerem metodologias sistematizadas, com avaliação constante do trabalho realizado no dia-a-dia, enquanto educadores (monitores). Nesse aspecto, também se faz necessário pensar em formas de avaliar o trabalho educativo desenvolvido, mesmo que este tenha que ser feito,

(...) com alto grau de provisoriedade, pois o dinamismo, a mudança, o movimento da realidade segundo o desenrolar dos acontecimentos, são as marcas que singularizam a educação não-formal (GOHN, 2006, p.32).

Ressalta-se que, geralmente, tanto na Comunidade Terapêutica como na escola a cultura organizacional ou estrutura educacional "condiciona" as pessoas a serem iguais, com o intuito de massificação. Os profissionais da educação, em sua maioria, acreditam que quanto mais iguais às pessoas se tornam, mais fácil será dirigi-las. Evidentemente que, nesta perspectiva da homogeneização é preciso exercer mecanismos disciplinares, atividades que coloquem em um único "modelo", a duração, o limite, o movimento, atitudes de todos os envolvidos, impondo aos seus corpos uma atitude de submissão. Assim, infelizmente, em alguns espaços educativos acaba-se por designar poder de dominação que não tolera as diferenças. Na verdade, ao posicionar-se perante o outro na qualidade de representantes hierárquicos de determinada prática social, seja com o intuito que for, acaba-se por se estabelecer uma relação, a rigor, impositiva e não raras vezes, violenta. Deve-se considerar que socialização (a inserção do indivíduo em uma sociedade) pressupõe a criação e o cumprimento de regras e preceitos norteadores das relações, de maneira que sejam preservados o diálogo, a cooperação e a troca entre o grupo social. Este tipo de atitude, coerciva, demonstra certo desconhecimento do significado da presença do político na ação educativa, e também do ético, em sua forma autêntica. Não importa o que se pensa sobre o mundo e nem quais são as concepções das pessoas ou da sociedade, para adolescentes e jovens o mundo é velho e, este sempre será mais velho do que elas, assim, a aprendizagem torna-se algo inevitavelmente do passado. Por isso, não é incomum encontrar, na escola, estudantes desmotivados e desinteressados em aprender. Falta aos professores, e, também, aos educadores (monitores) habilidade para articular esta aprendizagem com o novo. Uma formação continuada para profissionais da educação, independente de onde trabalhem, deve estar vinculada a um conhecimento mais profundo sobre a sociedade, de forma que os ajudem a conhecê-la melhor, e a partir daí, compartilhar conscientemente: regras, limites, questões relacionadas à justiça etc. Além da preocupação com a formação continuada destes profissionais, outro aspecto complicado é a composição do quadro de trabalhadores das Comunidades Terapêuticas. Esses educadores (monitores) são considerados como trabalhadores voluntários nos termos da legislação (BRASIL, 1996), inclusive declarando, via contrato, que o trabalho que realizam é voluntário. Esta prática é uma forma de burlar as leis trabalhistas, com diminuição de custos, e, geralmente, com o sacrifício da qualidade e do profissionalismo dos serviços prestados. Os educadores (monitores) quase sempre acabam reféns de uma espécie de sentimento de gratidão à comunidade terapêutica e quando confrontados com embates cotidianos com os residentes têm um posicionamento acrítico a situação. 
A terceira, e última, inquietação é o uso de medicações que se faz nestes locais desde que o crack se tornou uma grande epidemia. Os tratamentos passaram a utilizar medicações neurolépticas e outras para acalmar as crises de abstinência. Isso se tornou um problema sério e configurar-se como crime de exercício ilegal de medicina, quando um educador (monitor), que não é médico, indica e ministra remédios. Há ainda, outro caso extremo que é o de médicos que prescrevem remédios e não acompanham a ministração destes em seus pacientes. A prática de utilização de remédio como o Haldol Decanoato, entre outros, também pode constituir-se como crime de tortura, pois há casos em que sua utilização, sem acompanhamento médico psiquiátrico, pode causar intenso mal estar durante o quadro de abstinência, e há casos em que a medicação pode ser usada como punição para comportamentos tidos como inadequados. Estas situações vêm ocorrendo desde antes e mesmo depois da promulgação da lei (RDC 101/01 ANVISA) e exige uma discussão mais aberta e franca a respeito do problema, envolvendo áreas como saúde, educação, assistência social etc. A Comunidade Terapêutica deve estar em constante reflexão sobre questões a serem evitadas, como: falta de formação continuada para os educadores (monitores); desrespeito à legislação trabalhista; uso criminoso de medicações controladas, e quadros de práticas de violências (simbólicas e/ou de fato). Pois esta só será apta ao ensino se, e somente se, for apta para aprender e para mudar. Acredita-se que uma Comunidade Terapêutica deve, obrigatoriamente, se diferenciar efetivamente do modelo psiquiátrico, porque se assim não for, não há necessidade de sua existência.

Nesse sentido, reitera-se a importância da educação não-formal, na medida em que esta possibilita:

\begin{abstract}
A construção de relações baseadas em princípios de igualdade e justiça social, quando presentes num dado grupo social, fortalece o exercício da cidadania. A transmissão de informação e formação política e sociocultural é uma meta da educação não-formal. Ela prepara os cidadãos, educa o ser humano para a civilidade, em oposição à barbárie, ao egoísmo, individualismo etc. (GOHN, 2006, p. 30).
\end{abstract}

O risco da Comunidade Terapêutica não desenvolver a capacidade de fazer a autocrítica (no que a educação não-formal seria uma excelente ajuda) encontra-se na contradição que estabelece com seus princípios formadores, o que inviabilizaria sua proposta de tratamento. Na perspectiva da educação não-formal, educa-se não somente com um programa de tratamento determinado, mas, principalmente, com exemplos do cotidiano. A Comunidade Terapêutica surgiu como alternativa às rígidas estruturas do sistema psiquiátrico. Se ela mantiver um programa rígido semelhante ao modelo psiquiátrico, isto é, que não se repense a partir das práticas, dificilmente, poderá ser uma alternativa útil à sociedade.

Em fim, este debate ainda encontra-se no início de estudos que devem ser desenvolvidos com tempo. A questão da educação não-formal em Comunidades Terapêuticas necessita de investigações posteriores, com integração da área de educação, saúde, assistência social e poder judiciário. Urge a necessidade de pesquisas e estudos que aprofundem questões tão urgentes e importantes para a sociedade atual. 


\section{REFERÊNCIAS BIBLIOGRÁFICAS}

1. BAUMAN, Z. Comunidade: a busca por segurança no mundo atual. Tradução de Plínio Dentzien. Rio de Janeiro: Zahar, 2003.

2. BRASIL. Lei de Diretrizes e Bases da Educação Nacional: Lei 9.394/96. Disponível em: <http://portal.mec.gov.br/arquivos/pdf/ldb.pdf>. Acesso em: 17/01/2014.

3. BUCHER, R. Drogas e drogadição no Brasil. Porto Alegre: Artes Médicas, 1992.

4. DE LEON, G. A Comunidade Terapêutica: teoria, modelo e método. São Paulo: Ed. Loyola, 2003.

5. FRACASSO, L. Características da Comunidade Terapêutica. In: GUERRA, A. et al. (Org.). Curso nacional de aprendizado à distância: aspectos básicos no tratamento da dependência química. Brasília: SENAD, 2002.

6. GOHN, Maria da Glória. Educação não-formal, participação da sociedade civil e estruturas colegiadas nas escolas. Ensaio: aval. pol. públ. Educ., Rio de Janeiro, v.14, n.50, p. 27-38, jan./mar. 2006.

7. ISAÚDE.NET. Disponível em http://www.isaude.net/pt-BR/noticia/19424/saude-publica/abppede-revogacao-de-norma-da-anvisa-para-comunidades-terapeuticas. Acesso em $18 / 04 / 2015$.

8. MORRISH, I. Sociologia da educação. Tradução de Álvaro Cabral. 2. ed. Rio de Janeiro. Zahar, 1975. 